\title{
The contributions of phonology, orthography, and morphology in Chinese-English biliteracy acquisition
}

\author{
MIN WANG, CHEN YANG, and CHENXI CHENG \\ University of Maryland, College Park
}

Received: August 27, 2007 Accepted for publication: September 13, 2008

\author{
ADDRESS FOR CORRESPONDENCE \\ Min Wang, Department of Human Development, 3304C Benjamin Building, University of \\ Maryland, College Park, MD 20742. E-mail: minwang@umd.edu
}

\begin{abstract}
This study investigated the concurrent contributions of phonology, orthography, and morphology to biliteracy acquisition in 78 Grade 1 Chinese-English bilingual children. Conceptually comparable measures in English and Chinese tapping phonological, orthographic, and morphological awareness were administered. Word reading skill in English and Chinese was also tested. We found that crosslanguage phonological and morphological transfer occurs when acquiring two different writing systems. Chinese tone and onset awareness explained a significant amount of unique variance in English real-word reading after controlling for English-related variables. Chinese onset awareness alone made a significant unique contribution to variance in English pseudoword reading. Furthermore, English compound structure awareness explained unique variance in Chinese character reading. However, we did not see a significant cross-language transfer at the orthographic level. Taken together, these results suggest that there are shared phonological and morphological processes in bilingual reading acquisition, whereas the orthographic process may be language specific.
\end{abstract}

Word identification is the basic reading skill that children acquire in early literacy education. Word identification entails a cluster of constituent processes. The three major lexical constituents are orthography, phonology, and meaning (e.g., Plaut, McClelland, Seidenberg, \& Patterson, 1996; Seidenberg \& McClelland, 1989). The key development in learning to read is the improvement of the qualities of orthographic, phonological, and meaning representations of a given word. In other words, children learn to develop fully specified and precise phonological, orthographic, and semantic knowledge about the word (Perfetti, 1991, 1992). The present study examined the relationship among these three lexical constituents and word reading skill in a group of young Chinese-English bilingual children. We were particularly interested in the cross-language predictive power from these three constituents in acquiring bilingual word reading skill. Previous research has mainly focused on one or two constituents in studying their relationships to reading. For example, a large volume of literature has documented the

(C) 2009 Cambridge University Press 0142-7164/09 \$15.00 
critical contribution made by phonological processes to reading in both monolingual English-speaking children (e.g., Hulme et al., 2002; Perfetti, Beck, Bell, \& Hughes, 1987) and bilingual children (e.g., Durgunoglu, Nagy, \& Hancin-Bhatt, 1993, on Spanish-English bilingual children; Comeau, Cormier, Grandmaison, \& Lacroix, 1999, on French-English bilingual children). Our study sought to examine the three constituents concurrently to delineate the relative importance of each of the three constituents to word reading in a group of young Chinese-English bilingual children. We consider morphological awareness to be an important index in understanding meaning information in words. Indeed, morphological information is critical in processing meaning information in complex words (e.g., Shu, McBride-Chang, Wu, \& Liu, 2006).

\section{THE ROLES OF PHONOLOGICAL, ORTHOGRAPHIC, AND MORPHOLOGICAL AWARENESS IN LEARNING TO READ ENGLISH}

Previous research has provided evidence from separate studies to support the importance of phonological, orthographic, and morphological processing in learning to read in English. Phonological awareness generally refers to the ability to perceive and manipulate sound units of spoken language (Goswami \& Bryant, 1990). Orthographic awareness generally refers to children's understanding of the conventions used in the writing system of their language (Treiman \& Cassar, 1997). Morphological awareness concerns children's understanding of the morphemic structure of words and their ability to perceive and manipulate that structure (Carlisle, 1995). The role of phonological awareness in learning to read has received the most attention in the past two decades. Relatively less research has been devoted to studying the roles of orthographic awareness and morphological awareness.

Generally speaking, phonological awareness has been shown to be important for learning to read. A large body of literature has suggested that children's skill at processing the smallest phonological units (phonemes) is a powerful predictor of individual differences in learning to read, and that training children in phonemic-level skills can benefit their later reading progress (e.g., Byrne \& Fielding-Barnsley, 1995; Hulme et al., 2002; Lundberg, Frost, \& Petersen, 1988; Muter, Hulme, Snowling, \& Taylor, 1998). A great deal of literature has also suggested that phonological and orthographic knowledge mutually facilitate each other, and that grapheme-phoneme knowledge provides young readers with a powerful tool to bind the spelling patterns of individual and multiple letters with their pronunciations in words (e.g., Ehri, 1991, 1998). Empirical research suggests that this orthographic knowledge may contribute significantly to word recognition skill in children over and above phonological factors (e.g., Cunningham, Perry, \& Stanovich, 2001; Cunningham \& Stanovich, 1990, 1993).

There are three major types of morphological structures in English: compound, inflection, and derivation. Compound morphology is concerned with the formation of new words by combining two or more stem morphemes (e.g., cupcake). Inflectional morphology refers to the formation of new words to express grammatical features, such as singular/plural form (e.g., one flower $\rightarrow$ two flowers) or past/present tense (e.g., explain $\rightarrow$ explained). Derivational morphology refers to 
the formation of new words by adding morphemes to change the meaning of a stem morpheme without reference to the specific grammatical role a word might play in a sentence (e.g., the verb teach becomes the noun teacher by adding a suffix -er; however, the adjective possible remains an adjective, impossible, after adding a prefix -im). Children acquire these three types of morphological awareness at different rates. Acquisition of inflectional and compound morphology is completed earlier than derivational morphology, and has been related to reading progress during the first and second grades (Berko, 1958). Mastery of derivational morphology emerges later and takes longer, and has been shown to contribute to reading skill in later primary grades (e.g., Nagy, Berninger, \& Abbott, 2006; Nagy, Berninger, Abbott, Vaughan, \& Vermeulen, 2003).

There is a close relationship between morphological and phonological awareness. Researchers such as Carlisle and Nomanbhoy (1993) found that both phonological and morphological awareness contributed significantly to word reading in first graders, but the contribution of phonological awareness was greater. These results suggest that phonological sensitivity may provide a foundation for morphological learning. Because each morpheme is represented by a cluster of sounds, children must learn to segment the speech stream and identify those recurring sound units before they can identify the sound units that bear certain linguistic functions. Because two of the same morphemes can share the same or similar phonology, it is also possible that the observed morphological effect is indeed a sort of phonological effect.

Taken together, phonology, orthography, and morphology jointly contribute to learning to read English. Phonological awareness is an early precursor for successful reading later (e.g., Bradley \& Bryant, 1983). Knowledge of spelling patterns and morphological structures of written English words in turns promote understanding of both large and small units of phonological information. The three lexical constituents work together to facilitate word reading.

\section{THE ROLES OF PHONOLOGICAL, ORTHOGRAPHIC, AND MORPHOLOGICAL AWARENESS IN LEARNING TO READ CHINESE}

Chinese presents the highest contrast to the alphabetic writing system. The Chinese writing system does not possess the segmental structure that is basic to the alphabetic writing system. The principle of phonological assembly that, in alphabetic systems, allows larger (syllable and word) units to be assembled from letter-phoneme mappings, for example, /k/-/æ/-/t/ is assembled to make $/ \mathrm{k}$ t/, cannot apply in Chinese reading. However, because any written language is based on its spoken language, even in reading Chinese, phonological processing has been shown to be involved for skilled readers' reading (for a review, see Perfetti, Liu, \& Tan, 2005) and contribute to learning to read in young children (e.g., Ho \& Bryant, 1997a, 1997b, 1997c; Hu \& Catts, 1998; McBride-Chang \& Ho, 2000; Shu, Anderson, \& Wu, 2000). Although the literature indicates a role for phonological information in learning to read Chinese, it is important to note that phonological processing in Chinese is not at the phonemic level, but rather at the syllable or onset-rime level. 
Wang et al.: Chinese-English biliteracy acquisition

Orthography is important for reading Chinese. A Chinese character consists of interwoven strokes in a square-shape form that is in contrast to the linear arrangement of letters in most alphabetic orthographies. Current models of Chinese reading (e.g., Perfetti et al., 2005; Taft, Zhu, \& Peng, 1999) emphasize the importance of a fully specified orthographic representation prior to the activation of phonological and meaning information in reading Chinese. A series of studies suggest that orthographic processing is the basic processing component in reading Chinese (e.g., Peng, Li, \& Yang, 1997; Shu \& Anderson, 1999; Taft et al., 1999).

Because Chinese is often considered to be a "morphosyllabic" language in which the graphemes represent syllables that are morphemes rather than phonemes, and learning to read Chinese entails learning the grapheme-morpheme correspondences, it is reasonable to suggest that the role of morphological awareness in Chinese is significant, somewhat analogous to the role of phonemic awareness in reading English (Nagy et al., 2002). It is important to note that there are some important differences between Chinese and English morphology. There are no inflectional words and only a few derivational words in Chinese (Packard, 2000). Most Chinese words are compound words. For example, in a corpus of 17,430 characters, around $80 \%$ of the characters are constituents of bisyllable compound words (Kang, Xu, \& Sun, 2005). Chinese also has more homophones than English. A homophone refers to two or more syllables that share the same pronunciation, but have different meanings. For example, /jian/4 is a homophone in 建设 (construction) and 健康 (healthy). Chinese also has abundant homographs. A homograph refers to the same character that has different meanings. For example, the meaning of the character 手 (hand/occupation) in the word 水手 (sailor) is different from its meaning in another word 右手 (right hand), even though the sound and visual forms of 手 are the same in both cases. Several studies have shown that morphological awareness in Chinese, tapped by measures such as compound word formation, homophone detection, and homograph awareness strongly predicted Chinese character reading skill (Ku \& Anderson, 2003; Li, Anderson, Nagy, \& Zhang, 2002; McBride-Chang et al., 2005; McBride-Chang, Shu, Zhou, Wat, \& Wagner, 2003).

In sum, phonological, orthographic, and morphological awareness jointly contribute to learning to read Chinese, just like in English. However, unlike English, orthography and phonology are separated from each other in the majority of Chinese characters. For example, 火 represents the syllable / huo3/ and means fire. The number appearing after the syllable denotes the level of tone. Clearly, in this character there are no graphemes or letters that are mapped onto individual sounds in the syllable. Even though a great proportion of Chinese characters contains phonetic radicals, which provide some clue information for the pronunciations of the whole characters, the reliability of the prediction of pronunciations from phonetic radicals to whole characters is very low (at about 38\%; see Perfetti et al., 2005). Therefore, the contribution of phonology and orthography to reading Chinese could be relatively more independent as compared to English. Because of the "morphographic" nature of the Chinese writing system, the reliance on meaning information of morphemes is crucial in identifying Chinese words. In many cases, phonological and orthographic information may not be sufficient. 
Thus, morphological awareness is expected to contribute additionally to Chinese reading beyond phonological and orthographic information.

\section{CHINESE-ENGLISH BILITERACY ACQUISITION}

Research on Chinese-English biliteracy acquisition is emerging. The motivation of this line of research is to examine how the two languages and writing systems relate to each other in acquiring reading skills across different writing systems. One particular interest is to investigate whether the lexical constituent processes in one language can facilitate reading in another language. Previous literature has provided strong evidence supporting cross-language facilitation at the phonological level among different populations of bilingual children with various first language (L1) backgrounds, such as Spanish-English (e.g., Cisero \& Royer, 1995; Durgunoglu et al., 1993), French-English (e.g., Comeau et al., 1999), Italian-English (e.g., D’Angiulli, Siegel, \& Serra, 2001), and HebrewEnglish (e.g., Geva \& Siegel, 2000) bilingual children. These studies together demonstrated strong predictive power of phonological skills in children's L1 for reading skill in a second language (L2) within the alphabetic systems. The overall aim of the research on a Chinese-English population is to form comparisons of the cross-language relationships between children who are learning to read across different writing systems and those who are learning to read within the alphabetic systems. The examination of cross-language transfer has also been extended beyond the phonological level, to the orthographic and morphological levels. In the current literature, the term cross-language transfer has been used in a general way to indicate the tendency of learners to utilize knowledge and experience gained from one language in learning another language. Some researchers suggest that cross-language transfer arises from the shared or overlapping features of L1 and L2 (e.g., the grapheme-phoneme correspondences), and such transfer can occur between typologically related languages such as Spanish and English (e.g., Cisero $\&$ Royer, 1995). Other researchers suggest that bilingual facilitation can occur at a more abstract or systemic level. Children are able to apply their metalinguistic skills in one language to an even typologically distant language such as English and Chinese (e.g., Kuo \& Anderson, 2007).

Wang, Perfetti, and Liu (2005) investigated cross-language phonological and orthographic transfer among a group of Chinese-English bilingual children, in Grades 2 and 3 of their English and Chinese classes. Comparable experiments in Chinese and English were designed to focus on phonological and orthographic processing. Word reading skill in both writing systems was tested. The critical finding was that Chinese tone skill predicted English pseudoword reading over and above English phonemic processing skill. This finding suggests that even when children learn to read in two different writing systems, there is a level of phonological transfer. Tone is a suprasegmental feature of Chinese phonology that does not occur in the English phonological system. The four Chinese tones attached to the same syllable segment carry different lexical information. For example, the only difference between the syllable /man3/ and /man4/ is the tone. The first syllable with Tone 3 corresponds to 满, which means full, and the second syllable with Tone 4 corresponds to 慢, which means slow. The predictive power of Chinese 
tone awareness for English pseudoword reading was interpreted as reflecting some shared phonological sensitivity in learning to read Chinese and English. Chinese tone and English pseudoword reading both require children's attention to spoken word forms and their constituents, that is, the phonemes for English and tones for Chinese. The authors also suggested an alternative interpretation that a more general auditory processing skill is an underlying factor.

Wang et al. (2005), however, did not show a significant orthographic transfer. The authors argued that this result stemmed from the sharp contrasts between the Chinese and English writing systems. In summary, the authors suggest that in the case of Chinese-English bilingual reading, there may be a joint function of shared phonological processes and language-specific orthographic skill. These findings are important in delineating the universal and language-specific processes involved in learning to read two languages simultaneously.

Wang, Cheng, and Chen (2006) examined the contribution of morphological awareness to Chinese and English reading skill after taking into account phonological awareness among Chinese-English bilingual children in Grades 2 to 4. Two tasks assessing morphological awareness were used: a compound structure task and a derivational morphology task, in both Chinese and English. Their results showed that English compound awareness contributed to Chinese character reading and reading comprehension after taking into account Chinese-related variables. It seems that bilingual children are able to apply their knowledge about shared morphological structure from one language to reading in another language.

To provide a global picture of biliteracy acquisition in Chinese children, the present study sought to test the predictive value of phonology, orthography, and morphology concurrently in one study. We were particularly interested in the unique contribution of orthography in predicting reading skill across languages over and above phonology, the unique contribution of morphology over and above phonology and orthography. More specifically, we examined the role of phonological awareness in Chinese in predicting English word reading skill after considering within-English factors, the role of orthographic awareness in Chinese in predicting English word reading skill after controlling for within-English factors and phonological awareness in Chinese, and finally, the role of morphological awareness after controlling for within-English factors and phonological and orthographic awareness in Chinese. We also examined the roles of phonological, orthographic, and morphological awareness in English in predicting word reading skill in Chinese. This entry order of the variables in regression analyses allows us to address the unique contribution of orthography over and above phonology, and the unique contribution of morphology over and above phonology and orthography, given the close connections among the three variables. The focus of these analyses is also in line with previous research in examining the unique contribution of phonological, orthographic, and morphological awareness to reading skill among monolingual children (e.g., Cunningham et al., 2001; Deacon \& Kirby, 2004; Nagy et al., 2003). We recruited bilingual children from Grade 1 at both Chinese and English grade levels. These children were younger than in previous studies, which involved Grade 2 to Grade 4 children. We were interested in seeing if previous findings would hold for younger bilingual children. We used conceptually comparable phonological, orthographic, and morphological processing tasks in 
English and Chinese that have been tested in previous studies (Wang et al., 2005; Wang, Cheng, et al., 2006) and modified for the present study. We hypothesize that there will be cross-language transfer at the phonological level, given the universal phonological process involved in learning to read across different writing systems. If tone processing predicts English reading skill over and above English-related tasks, it suggests a level of phonological transfer for the contrastive phonological unit, which will replicate previous finding by Wang and colleagues (2005). We also expect to see morphological transfer from one language to reading skill in the other language. With regard to the orthographic constituent, we do not expect to see a significant cross-language transfer.

\section{METHOD}

\section{Participants}

Seventy-eight Chinese children from the Washington, DC, area participated in the study (40 boys, 38 girls). They attended English classes in American public schools during weekdays and a Chinese language school on weekends. All of them were enrolled in the first grade of Chinese classes and first grade of English classes. The mean age of these children was 6.81 years $(S D=0.36$ years). All of the children had normal English proficiency; their English school teachers made no reports concerning any problems with English proficiency. All of the children had normal intelligence; there were no reports from parents and teachers regarding any intellectual abnormality. The Pinyin system is taught in the Chinese schools. Children started to learn Pinyin in their kindergarten classes. Based on an interview with four classroom teachers, by the time children were in the spring semester of their first grade when the data collection took place (from February to March), they had reached a good mastery of Pinyin skill and were able to read and spell Pinyin without much difficulty. The spoken Chinese used in the school was Mandarin. Children learned a simplified version of the Chinese characters. Children's parents were asked to fill out a short questionnaire with basic demographic information and family language and literacy experiences. About $98 \%$ of the children were born in the United States, and $2 \%$ of them were born in Mainland China. About $60 \%$ of the parents reported that their children's first language was Chinese, and $6 \%$ reported that they learned the two languages simultaneously; the others $(35 \%)$ learned English as their first language. About $94 \%$ of the children spoke both Chinese and English at home, and $6 \%$ of the children only spoke Chinese at home. About $84 \%$ of the parents spoke both Chinese and English at home, and $16 \%$ of the parents only spoke Chinese at home. The majority of the families engaged in Chinese literacy activities such as reading Chinese books at home during the week.

\section{English measures}

Phoneme deletion task. Among phonological processing tasks, the phoneme deletion task has been shown to be the best predictor of reading skill in English (e.g., Stanovich, Cunningham, \& Cramer, 1984). From a CD player, children first 
Wang et al.: Chinese-English biliteracy acquisition

heard a nonword, and then were asked how this word would sound without a certain sound, followed by three choices. Each choice corresponded to a sign $(1,2$, or 3 ) on their answer sheet. The children's task was to circle the sign corresponding to the best answer among three choices. For example, "mab, how would mab sound without /b/? /ab/ (1), /mab/ (2), or /ma/ (3)?" Sixteen items in total were used, similar to those used by Wang et al. (2005; Wang, Cheng, et al., 2006). Two items each targeted the beginning and final consonants in the items containing only single consonants. Two items each targeted the first consonants in the initial and final consonant clusters. Four items each targeted the second consonants in the initial and final clusters. Three practice items were given to make sure that children understood the task.

Orthographic choice task. The task was similar to those used by Treiman (1993) and Siegel, Share, and Geva (1995), tapping into children's sensitivity to various orthographic patterns in English. For example, there is a legal position of certain double consonants; for example, "ff" does not occur at the beginning of a word. There are positional constraints for some consonant diagraphs; for example, "ck" is in a legal position in "dacker," whereas it is not in "ckader." Pseudowords were used in this task. Because English orthography cannot be fully dissociated from phonology, there was a potential confound of phonological legality in judging orthographic legality. We used the task from Wang et al. (2005) in which all of the items were carefully selected to ensure appropriate phonological legality. The children were shown a pair of stimuli, and asked to circle one of them that looked more like a read word. There were 18 items in total. Three examples were given.

Compound awareness task. To make the morphological tasks comparable between English and Chinese writing systems, we focused on compound awareness in addressing the contribution of morphological awareness to reading. In particular, we focused on compound structure awareness. This compound structure task assessed children's understanding of compound structure: that a compound word is made up of modifier and head, which is always the right-hand constituent in English. We adopted this measure with some modifications from Berninger and Nagy (1999) and Wang, Cheng, et al. (2006). Children read the items, while hearing the oral stimuli recorded by a native English speaker played over a CD player. Children were asked to circle the best answer. There were three subgroups in this task. In the first two subgroups, the children were presented with a riddle followed by two choices. The children's task was to choose the better answer to the riddle. The items in the two subgroups were identical except that the roles of nouns as modifier/head were exchanged. For example, if one of the items in the first group was "Which is a better name for a bee that lives in the grass: grass bee? Or bee grass?" an item in the second group would be "Which is the better name for grass where a lot of bees like to hide: bee grass? Or grass bee?" There were 14 of these items, 7 each in the first two subgroups. In the third subgroup, the children's task was to choose the best compound name for a short description among four choices, each of which included three to four morphemes. For example, "If you found a lid for a dish to keep candy in, what would it be called: Dish lid candy? Candy dish lid? Dish candy lid? Or Candy lid dish?" There were 4 items in the 
third subgroup. Eighteen items in total were included in this compound structure task.

Oral vocabulary. The Peabody Picture Vocabulary Test-III (PPVT-III; Dunn \& Dunn, 1997) was adapted as a measure of receptive vocabulary. The test was modified so that it could be administered to groups of children. Thirty items appropriate for the age group in our study were selected. The children heard a word from a CD player, and were asked to circle the picture that best represented the word given.

Real word naming. This task measures children's ability to recognize real English words. In this task children were instructed to read aloud each of the two words shown on a card. The words were adopted from the word recognition subtest of the Wide Range Achievement Test-Revised (Jastak \& Jastak, 1984). Children's responses were recorded via a digital voice recorder, which were then coded by a native English speaker. There were 35 items in total. For each item, a fully accurate pronunciation was given 1 point.

Real words can be read either via letter-phoneme mapping, an assembly route, or a whole word access lexical route. Our specific prediction is that English phonemic awareness may make a relatively weak contribution to reading English real words within English as shown in previous biliteracy studies (e.g., Wang et al., 2005; Wang, Park, \& Lee, 2006), and Chinese phonological awareness may have a relatively weak cross language transfer, in comparison to peudoword reading. Chinese tone awareness may have less contribution to English real word reading because reading real words requires less phonological sensitivity. English orthographic awareness would contribute to English real word reading within English; however, Chinese orthographic awareness would make little contribution to English real word reading. We did not expect to see a significant contribution from English compound task to English real word reading given the fact that compound awareness is less demanded in reading English words, and we also predict that little cross-language transfer from Chinese compound task would occur.

Pseudoword naming. This task measures children's letter-phoneme correspondence skills. Children were shown two items at a time on a card and were instructed to sound out the letter string aloud as best as he/she could. Forty items from the word attack subtest of the Woodcock Reading Mastery Test-Revised (Woodcock, 1987) were administered. Four examples were given. Children's naming responses were recorded via a digital voice recorder and coded by a native English speaker. Fully accurate pronunciations were given one point. If children pronounced more than half of the phonemes correctly, they received a score of 0.5 .

Because phonological awareness is essential in reading pseudowords, we predict that English phonemic awareness would make a great contribution to English pseudoword reading. We also predict that a stronger transfer from Chinese phonological awareness to English pseudoword reading would occur compared to English real word reading. Chinese tone awareness may contribute to English pseudoword reading, which would be consistent with previous findings in 
Wang et al.: Chinese-English biliteracy acquisition

Wang et al. (2005). English orthographic awareness may help reading English pseudowords if children could use an analogy strategy based on their real-word knowledge. We did not expect to see a significant transfer from Chinese orthographic awareness to English pseudoword reading. Neither English nor Chinese compound structure awareness is expected to contribute to English pseudoword reading.

\section{Chinese measures}

Onset, rime, and tone oddity. Chinese syllables can be analyzed into onset, rime, and tone. This task was selected to tap into children's ability to differentiate the phonological units (onset, rime, and tone) in syllables. This task was used in Wang et al. (2005) and modified in the present study. From a CD player, children heard three syllables recorded by a native Chinese speaker. On their answer sheets, the three syllables corresponded to signs of 1,2, and 3, respectively. The children's task was to choose which one of the three syllables did not share either the onset, rime, or tone with the other two syllables. There were 30 items in total, 10 in each condition. Two practice items were given for each condition.

Orthographic choice task. Children were presented with a pair of noncharacter stimuli on a card. They were instructed to choose the one that looked more like a real character. This task was similar to the one in Wang et al. (2005). Twentyfour items were included. There were two conditions with 12 items each: the first condition measured children's sensitivity to the legality of the radical position. One of the pairs of stimuli contained a component radical in an illegal position, for example, in the pair 奶 and 奶, 奶 contains a legal radical in an illegal position. The second condition measured children's sensitivity to the legality of the radical form. One of the pairs of stimuli contained a component radical with an illegal form, for example, in the pair 迕 and 这, 迕 contained an illegal radical. Illegal radicals were created by adding, deleting, or moving a stroke from one location to another within a legal radical. Three practice items were given.

Compound structure task. This task was comparable to the English compound structure task and was adopted from Wang, Park, et al. (2006) with some modifications. Because both Chinese and English are right-headed languages, the compound structure task can serve as a good comparable task between the two languages. Nonwords were used in this task. These compound nonwords were made up of free morphemes that can stand alone as a word. There were three subgroups in this task. In the first two subgroups, the children were asked to choose the better two-morpheme compound as an answer to a riddle. Again, the nouns being modified were exchanged between the first and second subgroups, just as in the English compound structure task. For example, “长在树上的花叫什么更好呢? 树花还是花树?" (Which is a better name for a flower that grows in a tree: A tree flower? Or a flower tree?), or “只长花的树叫什么更好呢? 树花或着花树?” (Which is a better name for a tree that grows a flower: A tree flower? Or a flower tree?). In the third subgroup, the children's task was to choose the best three-morpheme compound name for a short description among four choices. For example, “这里有 - 棵树, 上面有 
一只会吃虫子的鸟, 应该叫它什么呢? 鸟虫树? 虫鸟树? 树鸟虫? 还是虫树鸟?” (There is a tree with a bird that can eat bugs, what would it be called: Bird bug tree? Bug bird tree? Tree bird bug? Or bug tree bird?). Twelve items were included: 8 in the first two subgroups and 4 in the third subgroup.

Oral vocabulary. Thirty items were selected and translated from the PPVT-III (Dunn \& Dunn, 1997). There was no overlap between the Chinese and English vocabulary test items. The children were asked to circle the picture that best represented the word given.

Character naming. Twenty-five single characters and 15 two-character words were selected from the children's Chinese curriculum. On a 5-point scale, teachers were asked to rate a list of one-character and two-character words in terms of how familiar these written items were to the children. To ensure that the children were familiar with the words, the familiarity rating for each of the items was above 2 points. Similar to the English task, the children were asked to read the characters or words one at a time shown on a card. Each card had two characters, or words, on it. Children's responses were recoded via a digital voice recorder and scored by a native Chinese speaker. For each item, a fully accurate pronunciation was given 1 point.

We predict that Chinese phonological awareness would potentially contribute to Chinese character reading. Chinese orthographic awareness should also predict Chinese character reading. Both Chinese and English compound structure awareness is expected to contribute to Chinese character reading given the nature that compound awareness is more demanded in reading Chinese characters.

\section{Procedure}

English naming and Chinese character naming tasks were administered individually. The remaining tasks were administered in groups in quiet classrooms. The tasks were divided into four sessions, two sessions each for each language. Each session lasted about 25-30 min. Children were given a short break in the middle of each session. The order of the two sessions in each language was counterbalanced, and the order of the two languages tested was also counterbalanced among the groups of children. Children received small school-related gifts at the end of each testing session.

\section{RESULTS}

Means and standard deviations are listed in Table 1, as well as the reliabilities for all of the measures. All of the measures had good reliabilities except the Chinese compound structure task, which had a relatively low reliability of .34 . Children's performance on the orthographic choice task in English and Chinese was both significantly above chance level, both $t \mathrm{~s}(77)>11.90, p \mathrm{~s}<.001$. Their performance on the first two subgroups of the compound awareness task, which involved a two-morpheme compound structure and had a high chance factor, was 
Table 1. Reliabilities, mean percentage correct, and standard deviations of all measures

\begin{tabular}{lccc}
\hline \hline & $\alpha$ & Mean & $S D$ \\
\hline English tasks & & & \\
$\quad$ Oral vocabulary & .82 & 0.40 & 0.14 \\
Phoneme deletion & .83 & 0.66 & 0.22 \\
Orthographic choice & .79 & 0.77 & 0.12 \\
Compound structure & .76 & 0.58 & 0.19 \\
Real word reading & .97 & 0.46 & 0.12 \\
Pseudoword reading & .90 & 0.75 & 0.18 \\
Chinese tasks & & & \\
Oral vocabulary & .78 & 0.58 & 0.17 \\
Onset awareness & .82 & 0.58 & 0.28 \\
Rime awareness & .82 & 0.64 & 0.30 \\
Tone awareness & .64 & 0.49 & 0.23 \\
Orthographic choice & .70 & 0.68 & 0.13 \\
Compound structure & .34 & 0.52 & 0.17 \\
Character reading & .83 & 0.30 & 0.11 \\
\hline \hline
\end{tabular}

also significantly above chance level, both $t$ s $(77)>5.16, p$ s $<.001$ for both Chinese and English.

\section{Correlations among all variables}

Bivariate correlations among all of the Chinese and English tasks, including age, are shown in Table 2. We observed that for reading English, oral vocabulary was significantly correlated with the compound structure task $(r=.40, p<.01)$ and the two reading tasks $(r=.36$ for both real word and pseudoword reading, both $p$ s $<.01)$. English phoneme deletion and orthographic choice tasks were both significantly correlated with the two reading tasks (all $p \mathrm{~s}<.05$ ). The English compound structure task was significantly correlated with the two reading tasks $(r=.30$ and .29 , respectively, both $p \mathrm{~s}<.05$ ).

For reading Chinese, oral vocabulary was significantly correlated with the compound structure task $(r=.28, p<.05)$ and character reading $(r=.29, p<$ $.05)$. Chinese onset awareness was significantly correlated with character reading $(r=.30, p<.01)$. The Compound structure task was significantly correlated with character reading, as well $(r=.30, p<.01)$.

For cross-language correlations, both English phoneme deletion and orthographic choice did not significantly correlate with any of the Chinese measures. The English compound structure task was correlated with Chinese character reading $(r=.33, p<.01)$. The three Chinese phonological tasks were all significantly correlated with English real and pseudoword reading tasks. For example, between Chinese onset awareness and the English real word and pseudoword reading tasks respectively, correlations were $r=.43$ and .50 (both $p \mathrm{~s}<.01$ ). 
Table 2. Correlations among age and Chinese and English tasks

\begin{tabular}{|c|c|c|c|c|c|c|c|c|c|c|c|c|c|c|}
\hline & 1 & 2 & 3 & 4 & 5 & 6 & 7 & 8 & 9 & 10 & 11 & 12 & 13 & 14 \\
\hline 1. Age & - & & & & & & & & & & & & & \\
\hline \multicolumn{15}{|c|}{ English Tasks } \\
\hline 2. Oral vocabulary & .16 & 一 & & & & & & & & & & & & \\
\hline 3. Phoneme deletion & -.06 & .20 & - & & & & & & & & & & & \\
\hline 4. Orthographic choice & -.03 & .18 & $.27 *$ & - & & & & & & & & & & \\
\hline 5. Compound structure & .02 & $.40 * *$ & .17 & .16 & - & & & & & & & & & \\
\hline 6. Real word reading & .10 & $.36 * *$ & $.25 *$ & $.34 * *$ & $.30 * *$ & - & & & & & & & & \\
\hline 7. Pseudoword reading & .09 & $.36 * *$ & $.31 * *$ & $.33 * *$ & $.29 *$ & $.78 * *$ & - & & & & & & & \\
\hline
\end{tabular}

Chinese Tasks

\begin{tabular}{|c|c|c|c|c|c|c|c|c|c|c|c|c|c|}
\hline 8. Oral vocabulary & -.07 & .11 & -.02 & -.10 & .10 & -.22 & $-.23 *$ & - & & & & & \\
\hline 9. Onset awareness & .04 & $.33 * *$ & .08 & .11 & $.28 *$ & $.43 * *$ & $.50 * *$ & .08 & - & & & & \\
\hline 10. Rime awareness & .02 & $.30 * *$ & .00 & .16 & $.24 *$ & $.30 * *$ & $.31 * *$ & .20 & $.66^{* *}$ & - & & & \\
\hline 11. Tone awareness & .04 & .20 & -.07 & .22 & .16 & $.43 * *$ & $.33 * *$ & .00 & $.34 * *$ & $.30 * *$ & 一 & & \\
\hline 12. Orthographic choice & -.12 & $-.22 *$ & -.03 & .04 & .11 & .00 & .01 & .04 & .09 & .20 & .08 & - & \\
\hline 13. Compound structure & .02 & .11 & .06 & .18 & .13 & -.05 & .08 & $.28 *$ & .13 & .12 & -.06 & .10 & - \\
\hline 14. Character reading & $-.28 *$ & .19 & .12 & .13 & $.33 * *$ & .11 & $.27 *$ & $.29 *$ & $.30 * *$ & .19 & .11 & .19 & $.30 * *$ \\
\hline
\end{tabular}

$* p<.05 . * *<.01$. 
Wang et al.: Chinese-English biliteracy acquisition

\section{Cross-language transfer of phonological, orthographic, and morphological awareness}

In this section, we focus our analyses on cross-language transfer of phonological, orthographic, and morphological awareness between Chinese and English. We were interested in whether phonological, orthographic, and morphological skills contributed unique variance to reading from one language to the other. Using a set of hierarchical regression analyses, we first investigated the variables that predict English real word reading and pseudoword reading using both English and Chinese tasks. Our goal was to determine whether Chinese tasks explained a significant amount of variance in English reading skills after English tasks were taken into consideration. Second, we investigated the variables that predict Chinese character reading using both Chinese and English tasks. Similar to the analyses of English reading, we aimed to determine the unique variance in Chinese reading skills accounted for by English phonological, orthographic, and morphological skills. Age was always entered first to control for its effect. PPVT scores were entered after age to control for the effect of oral vocabulary.

For predicting English real word and pseudoword reading in separate analyses, the order of entry was age, English oral vocabulary, English phoneme deletion, English orthographic choice, English morphological task, and Chinese phonological, orthographic, and morphological tasks. Scores for Chinese tasks were entered after the English tasks to examine the unique variance explained by Chinese phonological, orthographic, and morphological skills over and above the English tasks. For both within and cross-language predictors, scores for orthographic tasks were entered after phonological tasks to examine the unique variance explained by orthographic skills after considering the phonological tasks. This order is relevant for English only because Chinese phonology and orthography are mutually independent of each other. Scores for morphological tasks were entered after phonological and orthographic tasks to explore the unique variance explained by morphological skill after considering phonological and orthographic tasks. To reiterate, the purpose of this above entry order was to separate phonology and orthography in English, and to separate morphology from phonology and orthography in both English and Chinese. The three Chinese phonological tasks were entered into one block using a stepwise method to identify the best predictor within phonological awareness in Chinese.

For predicting Chinese character reading, the order of entry was age, Chinese oral vocabulary, Chinese phonological tasks, Chinese morphological task, and English phoneme deletion, English orthographic and English morphological tasks. A similar stepwise method was used to enter the three Chinese phonological tasks. Results of the analyses predicting English reading are shown in Tables 3 and 4 and of predicting Chinese character reading in Table 5. Information on $R^{2}$ changes, as well as final standardized beta weights, is provided.

Results of cross-language prediction. In predicting English reading, we observed that Chinese tone and onset awareness predicted English real word reading (11\%, $p<.01$, and $5 \%, p<.05$, respectively), and Chinese onset awareness also predicted English pseudoword reading $(14 \%, p<.001)$ after controlling for all of the 
Wang et al.: Chinese-English biliteracy acquisition

Table 3. Hierarchical regression analyses predicting English real word reading using English and Chinese tasks

\begin{tabular}{|c|c|c|c|c|c|}
\hline Variables & Mult. $R$ & Mult. $R^{2}$ & $R^{2}$ Change & $F$ Change & $\beta$ \\
\hline Step 1: Age & 0.10 & 0.01 & 0.01 & 0.72 & 0.07 \\
\hline Step 2: English oral vocabulary & 0.36 & 0.13 & 0.12 & $10.52 * *$ & 0.12 \\
\hline $\begin{array}{l}\text { Step 3: English phoneme } \\
\text { deletion }\end{array}$ & 0.41 & 0.17 & 0.03 & 3.05 & 0.16 \\
\hline $\begin{array}{l}\text { Step 4: English orthographic } \\
\text { choice }\end{array}$ & 0.47 & 0.22 & 0.06 & $5.52 *$ & 0.19 \\
\hline $\begin{array}{l}\text { Step 5: English compound } \\
\text { structure }\end{array}$ & 0.49 & 0.24 & 0.02 & 1.69 & 0.09 \\
\hline $\begin{array}{l}\text { Step 6: Chinese tone awareness } \\
\text { Chinese onset awareness }\end{array}$ & $\begin{array}{l}0.59 \\
0.63\end{array}$ & $\begin{array}{l}0.35 \\
0.40\end{array}$ & $\begin{array}{l}0.11 \\
0.05\end{array}$ & $\begin{array}{l}12.20 * * \\
5.33 *\end{array}$ & $\begin{array}{l}0.26^{*} \\
0.26^{* *}\end{array}$ \\
\hline $\begin{array}{l}\text { Step 7: Chinese orthographic } \\
\text { choice }\end{array}$ & 0.63 & 0.40 & 0.00 & 0.07 & -0.01 \\
\hline $\begin{array}{l}\text { Step 8: Chinese compound } \\
\text { structure }\end{array}$ & 0.65 & 0.42 & 0.02 & 2.06 & 0.14 \\
\hline
\end{tabular}

$* p<.05 . * * p<.01$.

Table 4. Hierarchical regression analyses predicting English pseudoword reading using English and Chinese tasks

\begin{tabular}{|c|c|c|c|c|c|}
\hline Variables & Mult. $R$ & Mult. $R^{2}$ & $R^{2}$ Change & $F$ Change & $\beta$ \\
\hline Step 1: Age & 0.09 & 0.01 & 0.01 & 0.58 & 0.07 \\
\hline Step 2: English oral vocabulary & 0.36 & 0.13 & 0.12 & $10.38 * *$ & 0.12 \\
\hline $\begin{array}{l}\text { Step 3: English phoneme } \\
\quad \text { deletion }\end{array}$ & 0.43 & 0.19 & 0.06 & $5.56^{*}$ & $0.19 *$ \\
\hline $\begin{array}{l}\text { Step 4: English orthographic } \\
\text { choice }\end{array}$ & 0.49 & 0.24 & 0.05 & $4.59 *$ & $0.21 *$ \\
\hline $\begin{array}{l}\text { Step 5: English compound } \\
\text { structure }\end{array}$ & 0.50 & 0.25 & 0.01 & 1.34 & 0.06 \\
\hline $\begin{array}{l}\text { Step 6: Chinese onset } \\
\text { awareness }\end{array}$ & 0.63 & 0.39 & 0.14 & $16.67 * *$ & $0.41 * *$ \\
\hline $\begin{array}{l}\text { Step 7: Chinese orthographic } \\
\text { choice }\end{array}$ & 0.63 & 0.39 & 0.00 & 0.01 & 0.01 \\
\hline $\begin{array}{l}\text { Step 8: Chinese compound } \\
\text { structure }\end{array}$ & 0.63 & 0.40 & 0.00 & 0.24 & 0.05 \\
\hline
\end{tabular}

${ }^{*} p<.05 .{ }^{*} p<.01$.

English-related tasks. Beta weights were all significant as well ( $p$ s $<.05)$. The Chinese orthographic and morphological tasks failed to emerge as significant predictors in both regression equations. In predicting Chinese character reading, the English compound structure task contributed a significant amount of unique 
Wang et al.: Chinese-English biliteracy acquisition

Table 5. Hierarchical regression analyses predicting Chinese character reading using Chinese and English tasks

\begin{tabular}{|c|c|c|c|c|c|}
\hline Variables & Mult. $R$ & Mult. $R^{2}$ & $R^{2}$ Change & $F$ Change & $\beta$ \\
\hline Step 1: Age & 0.28 & 0.08 & 0.08 & $6.46^{*}$ & $-0.27 * *$ \\
\hline Step 2: Chinese oral vocabulary & 0.39 & 0.15 & 0.07 & $6.42 *$ & 0.18 \\
\hline $\begin{array}{l}\text { Step 3: Chinese onset } \\
\text { awareness }\end{array}$ & 0.48 & 0.24 & 0.08 & $8.09 * *$ & 0.19 \\
\hline $\begin{array}{l}\text { Step 4: Chinese orthographic } \\
\text { choice }\end{array}$ & 0.50 & 0.25 & 0.01 & 1.36 & 0.08 \\
\hline $\begin{array}{l}\text { Step 5: Chinese compound } \\
\text { structure }\end{array}$ & 0.54 & 0.29 & 0.04 & $4.06^{*}$ & 0.19 \\
\hline $\begin{array}{l}\text { Step 6: English phoneme } \\
\text { deletion }\end{array}$ & 0.54 & 0.30 & 0.01 & 0.62 & 0.04 \\
\hline $\begin{array}{l}\text { Step 7: English orthographic } \\
\text { choice }\end{array}$ & 0.55 & 0.30 & 0.00 & 0.28 & 0.04 \\
\hline $\begin{array}{l}\text { Step 8: English compound } \\
\quad \text { structure }\end{array}$ & 0.58 & 0.34 & 0.04 & $4.35^{*}$ & $0.22 *$ \\
\hline
\end{tabular}

$* p<.05 . * * p<.01$.

variance even when entered as the last step $(4 \%, p<.05$, the beta weight was also significant, $p<.05)$, that is, after taking into account all of the Chineserelated tasks as well as the English phonological, orthographic, and morphological tasks.

Results of within-language prediction. English oral vocabulary contributed significantly to English real word and pseudoword reading (12\% in both cases, both $p$ s $<.01)$. However, both beta weights were not statistically significant. English phoneme deletion explained a significant amount of variance in reading English pseudowords $(6 \%, p<.05$, the beta weight was also significant, $p<.05)$, but explained a smaller amount in reading English real words $(3 \%, p=.09)$. The English orthographic task predicted a significant amount of variance in both English real and pseudoword reading after taking into account the English phoneme deletion task $(6 \%$ and $5 \%$, respectively, both $p \mathrm{~s}<.05)$. The beta weight was significant for pseudoword reading only. The English compound structure task did not turn out to be a significant predictor after controlling for phonological and orthographic tasks.

Chinese oral vocabulary contributed significantly to Chinese character reading $(7 \%, p<.05)$. Chinese onset awareness explained a significant amount of variance in Chinese character reading $(8 \%, p<.01)$, however, the Chinese orthographic task failed to do so. The Chinese compound structure task, in contrast, which turned out to be the significant predictor, predicted a modest but significant amount of variance $(4 \%, p<.05)$ after controlling for the Chinese phonological and orthographic tasks. All of the beta weights did not reach statistical significance. 
The present study set out to examine the unique contribution of phonology, orthography, and morphology, the three key lexical constituents, in Chinese-English biliteracy acquisition in beginning readers. Our focus was to examine the unique contribution of orthography over and above phonology and the unique contribution of morphology over and above phonology and orthography. Previous research has only targeted one or two of the lexical components in studying bilingual reading acquisition (e.g., Wang et al., 2005; Wang, Cheng, et al., 2006). Our study incorporated all three constituents concurrently to provide a global picture of biliteracy learning. We hypothesized that there are shared phonological processes in learning to read different languages. We also hypothesized that morphological awareness from one language facilitates reading skill in another language. Our results indeed showed a strong cross-language phonological transfer from Chinese to English. Chinese tone and onset awareness each explained a significant amount of unique variance in English real word reading after taking into account English-related variables including oral vocabulary, phonemic, orthographic, and morphological awareness. Tone contributed more unique variance than onset awareness. Chinese onset awareness alone also explained a significant amount of unique variance in English pseudoword reading. The transfer of Chinese tone awareness to English real word reading skill was consistent with that found in Wang et al. (2005), even though the transfer was from Chinese tone to English pseudoword reading in their study. The contribution of Chinese onset awareness to English word reading is a novel finding that has not been presented in previous Chinese-English biliteracy research (e.g., Wang et al., 2005).

These findings of cross-language phonological transfer support the hypothesis that there is a joint function of shared phonological processes in biliteracy acquisition (Wang et al., 2005). The overall finding of tone transfer indicated that there was a unique level of relationship between these two languages that differs from the phonemic level relationship common to two alphabetic systems. Two potential interpretations may be useful in understanding the underlying mechanism that links Chinese tone and English reading together. The first one, proposed by Wang et al. (2005), is that general auditory processing might be the underlying factor: the auditory hypothesis. Some researchers (e.g., Reed, 1989; Tallal, 1980) have found evidence to support a relationship between auditory perception and reading skills in English. For example, Tallal (1980) compared auditory processing skills in a group of children with dyslexia to a group of children with normal reading ability. The two tones used in the auditory task in Tallal's study, as well as other studies, were either high or low frequency. Her results showed that for both samedifferent and tone-order judgment tasks, the children made more errors when the interstimulus interval decreased. The error rate of the children with dyslexia was significantly higher compared to children with typical reading skill when the interstimulus interval was short. This result suggested that temporal auditory processing is an important skill that children with dyslexia lack (for different results and arguments, see also Bretherton \& Holmes, 2003; Share, Jorm, Maclean, \& Russel, 2002). Chinese tone indeed entails pitch processing; nevertheless, it is fundamentally different from the one used in Tallal and others' research. First, 
Wang et al.: Chinese-English biliteracy acquisition

Chinese tone is more complex acoustically than that used in Tallal and others' research. Second, we wanted to emphasize that tone in Chinese is not only an auditory process but also a phonetic process. The tone is carried on a vowel and has lexical function.

To take into account the phonological information embedded in the Chinese tone, we propose another potential hypothesis. We suggest that sensitivity to prosodic features of languages may be responsible for the contribution of Chinese tone to English reading: the prosody hypothesis. A number of studies have shown that speakers of different languages are sensitive to different prosodic features of the spoken language. Results from these studies indicate the importance of stress units for English speakers (e.g., Cutler \& Butterfield, 1992), syllables for French speakers (e.g., Cutler, Mehler, Norris, \& Segui, 1986), and morae for Japanese speakers (e.g., Cutler \& Otake, 1994). More recent research further shows that the prosodic property of lexical stress in English affects eye movements in silent reading (Ashby \& Clifton, 2005). Ashby and Clifton demonstrated that readers took more time to read and spent more time fixating on words with two stress syllables compared to words with one stress syllable. This key finding shows that suprasegmental properties of spoken words (i.e., stress) affect not only oral but also written language processing. If Chinese tone is considered a type of prosodic feature in spoken language, then we would suggest that Chinese tone may be useful in reading not only Chinese but may also contribute to English word reading for Chinese children learning to read English L2.

The reason that tone predicted English real word reading only in our study is probably due to the fact that real words are more associated with the stress feature of English words than pseudowords. This may better support our prosody hypothesis. The finding that Chinese tone predicted English pseudoword reading only in Wang et al. (2005) may better support the auditory hypothesis; in other words, general auditory skill may be a correlate of both Chinese tone and English pseudoword reading skill.

Chinese onset awareness also contributed to both English real word and pseudoword reading. This result may stem from the fact that the onset is a shared phonological unit between Chinese and English. Even though the onset is considered to be a relatively easy phoneme to perceive and manipulate in a syllable in Chinese and English, it is clear that onset awareness in Chinese facilitated children's reading skill in English. It is interesting that both the shared (onset) and contrastive (tone) phonological units jointly contributed to reading in English; and it contributes to our better understanding of cross language phonological transfer at both levels of shared and contrastive features. The significant contribution of Chinese onset awareness to English reading was not shown in Wang et al. (2005). It could be due to the fact that younger children (i.e., Grade 1) were recruited in the present study compared to those in Wang et al. (2005) who were in Grades 2 and 3. Moreover, the task demand was also slightly different between the two studies. Our onset task was an oddity task in which the children had to select the stimuli that had a different onset from three choices; whereas Wang and colleagues used a relatively easier matching task paradigm in which the children were asked to select one between two choices that matched the onset of the target stimuli. Clearly, the working memory load was greater in the oddity task compared to the 
matching task. As a result, children in our study had much poorer performance than those in Wang et al. (2005; the accuracy rate was .58 vs. .94). Therefore, it is likely that the explanatory power of Chinese onset awareness for English reading could be limited in older children when almost ceiling performance occurred in Wang et al. (2005).

It is important to note that the Chinese children in the present study learned Pinyin before they started to learn Chinese characters. Given the alphabetic nature of the Pinyin system, Pinyin learning experience may have facilitated the phonological transfer from Chinese to English. We speculate that for Chinese children without Pinyin learning experience, such as Cantonese-English bilingual children, such phonological transfer could be very much reduced. Previous research has also shown that Chinese readers who are experienced in using Pinyin to learn to read are more successful in manipulating speech sounds than those who are literate only in Chinese characters (e.g., Read, Zhang, Nie, \& Ding, 1986). Finally, it is plausible that phonological awareness indeed predicts reading ability even across languages among Chinese-English bilingual children; however, it is equally plausible that learning to read (e.g., Pinyin or English) may have reciprocally promoted phonological awareness among young Chinese children.

Cross language phonological transfer occurred from Chinese to English, but not from English to Chinese. One possible reason is that our English phoneme deletion task was designed to target children's skill in processing fine-grained phonemic information in English words. Most of the items involved deletion of a particular phoneme from a beginning or ending consonant cluster. Therefore, this level of phonological skill may not help in reading Chinese characters, because the mapping of phonology and orthography in the Chinese writing system does not entail such detailed phonological manipulation.

We also found cross-language morphological transfer in learning to read Chinese and English simultaneously. English compound structure awareness contributed to Chinese character reading over and above the Chinese tasks. This result is consistent with Wang, Cheng, et al. (2006), suggesting that cross-language facilitation in bilingual reading acquisition can occur not only at the phonological processing level (surface form) but also at the meaning processing level (function). One interpretation of this finding is that the cross-language morphological transfer may stem from the shared morphological structure between Chinese and English writing systems, that is, the compound structure. Children are able to apply morphological knowledge from one language to reading in another language that shares a similar structure.

One potential explanation for the asymmetry in the phonological and morphological transfer may lie in the differing strength of the contribution of phonological and morphological factors in learning to read Chinese and English. Previous research comparing learning to read Chinese and English in monolingual children revealed a stronger phonological contribution in English and a stronger morphological contribution in Chinese (e.g., McBride-Chang et al., 2005). Therefore, it seems reasonable to expect that morphological contribution is more easily detected in Chinese than phonological contribution and phonological contribution is more easily detected in English than morphological contribution. 
Wang et al.: Chinese-English biliteracy acquisition

It appears that there was no cross-language orthographic transfer in learning to read two different writing systems, a result consistent with Wang et al. (2005). This finding suggests that there is a writing system specific component in biliteracy acquisition. We argue that this result reflects the contrasts in mapping principles and visual forms across the two writing systems. The consequence of these contrasts was the difficulty in transfer of orthographic skills from Chinese to English and vice versa. Recent neuroimaging work on Chinese-English bilingual adults (e.g., Liu \& Perfetti, 2003; Tan et al., 2001, 2003) has showed evidence suggesting that reading Chinese involves more activation in some brain areas that are responsible for coordinating and integrating visual-spatial analyses of logographic Chinese characters compared with reading English.

There were also some interesting results from the within-language analyses. In reading English, the orthographic choice task contributed to reading real words, whereas both phoneme deletion and orthographic choice contributed to reading pseudowords. These results indicated that both phonology and orthography are important in learning to read English in a young bilingual population. These results are consistent with previous literature on roles of phonology and orthography in learning to read alphabetic languages (e.g., Cunningham et al., 2001; Ehri, 1991, 1998; Goswami \& Bryant, 1990; Hulme et al., 2002; Lundberg, Olofsson, \& Wall, 1980; Perfetti, 1992; Share, 1995). In the present study, we found that phoneme deletion predicted a significant amount of variance in pseudoword reading, but not in real-word reading. This result is understandable given the previous research suggesting that real words can be read either via letter-phoneme mapping, an assembly route, or a whole-word access, a lexical route, as was described in the well-known dual-route reading model (e.g., Coltheart, 1978; Coltheart, Curtis, Atkins, \& Haller, 1993; Coltheart, Rastle, Perry, Langdon, \& Ziegler, 2001). Therefore, real-word reading may not be as sensitive to phonemic processing skills as is pseudoword reading.

In reading Chinese, in contrast, onset awareness predicted Chinese character reading, and compound structure awareness predicted a unique amount of variance after considering phonology. These results revealed that both phonological and morphological awareness are important in learning to read Chinese. It is surprising that Chinese orthographic processing did not contribute to reading Chinese characters. This result is in contrast with Wang et al.'s (2005) findings in which the Chinese orthographic task contributed a significant amount of variance to reading Chinese characters. The discrepancy of the findings in these two studies is probably due to the age of the children recruited. The present study included rather young children, that is, Grade 1 in the Chinese school, whereas Wang et al. recruited children in Grades 2 and 3. Younger children performed more poorly on tasks requiring understanding of Chinese orthographic structures. Their accuracy on the orthographic choice task was also much lower than that in Wang et al. (.68 vs. .89). Therefore, overall poor orthographic knowledge may not be able to facilitate reading characters. In a post hoc analysis, we divided the children into two groups: low versus high orthographic awareness. The low group all had response accuracy rates lower than $.60(N=22)$, and the high group all had rates higher than $.60(N=$ 56). The means (standard deviations) of the two groups were .51 (.07) and .74 (.08), respectively. We further calculated partial correlations between the orthographic 
awareness and Chinese word reading skill after controlling for age, Chinese oral vocabulary, and Chinese phonological (onset) awareness. We found that there was an increase in the partial correlation from -.06 to .22 between the low and high group. It seems that there is an increasingly close relationship between Chinese orthographic awareness and Chinese word reading when children's orthographic awareness improves. In a future study, the same children could be followed to a higher grade and monitored to see if a significant prediction from children's Chinese orthographic awareness to character reading skill emerges. A longitudinal study would allow for tracking the changes of children's language and reading skill over time and possibly establishing some causal relationship among the phonological, orthographic, and morphological predictors and word reading skill at both the within language and cross-language levels. Future research also needs to improve the reliability of the Chinese compound structure task. Careful item analyses of the task help to identify poor items. A more comprehensive measure such as the compound construction task used in other studies (e.g., McBride-Chang et al., 2003, 2005) may be worth considering in future research. In the compound construction task, instead of being asked to select a correctly ordered compound word according a description sentence as used in our study, children were asked to actively construct compound words for newly presented objects or concepts.

\section{CONCLUSION}

In summary, our study concurrently examined the contribution of phonology, orthography, and morphology in Chinese-English biliteracy acquisition in a group of Grade 1 children. Our results suggest the existence of cross-language phonological and morphological transfer in acquiring two different writing systems. The phonological transfer occurred for both onset awareness, the shared phonological unit, and awareness of tone, the contrastive phonological unit. This is a novel finding compared to previous Chinese-English biliteracy research (e.g., Wang et al., 2005). Cross-language morphological transfer occurred for compound structure awareness. However, we did not find any cross-language transfer at the orthographic level. These results together highlight the shared phonological and morphological processes in bilingual reading acquisition. The orthographic process, however, may be language specific, at least in the case of learning to read across the writing systems.

\section{ACKNOWLEDGMENTS}

This study was supported by a NIH/NICHD Grant (R01HD048438). We appreciate the Chinese language school teachers and children for their warm support. We thank Kendra Sun-Alperin, Amy Dai, Jing Tian, Min Liu, and Ruizhi Pei for their wonderful assistance in testing children and scoring data. Emily Fox carefully proofread the manuscript.

\section{REFERENCES}

Ashby, J., \& Clifton, C. (2005). The prosodic property of lexical stress affects eye movements during silent reading. Cognition, 96, 89-100. 
Wang et al.: Chinese-English biliteracy acquisition

Berko, J. (1958). The child's learning of English morphology. Word, 14, 150-177.

Berninger, V., \& Nagy, W. (1999). Morphological Awareness Battery. Unpublished manuscript, University of Washington.

Bradley, L., \& Bryant, P. E. (1983). Categorizing sounds and learning to read: A causal connection. Nature, 301, 419-421.

Bretherton, L., \& Holmes, V. M. (2003). The relationship between auditory temporal processing, phonemic awareness, and reading disability. Journal of Experimental Child Psychology, 84, 218-243.

Byrne, B., \& Fielding-Barnsley, R. (1995). Evaluation of a program to teach phonemic awareness to young children: A 2- and 3-year follow-up and a new preschool trial. Journal of Educational Psychology, 87, 488-503.

Carlisle, J. (1995). Morphological awareness and early reading achievement. In L. B. Feldman (Ed.), Morphological aspects of language processing (pp. 189-209). Hillsdale, NJ: Erlbaum.

Carlisle, J. F., \& Nomanbhoy, D. (1993). Phonological and morphological awareness in first graders. Applied Psycholinguistics, 14, 177-195.

Cisero, C. A., \& Royer, J. M. (1995). The development and cross-language transfer of phonological awareness. Contemporary Educational Psychology, 20, 275-303.

Coltheart, M. (1978). Lexical access in simple reading tasks. In G. Underwood (Ed.), Strategies of information processing (pp. 151-216). New York: Academic Press.

Coltheart, M., Curtis, B., Atkins, P., \& Haller, M. (1993). Models of reading aloud: Dual-route and parallel-distributed-processing approaches. Psychological Review, 100, 589-608.

Coltheart, M., Rastle, K., Perry, C., Langdon, R., \& Ziegler, J. (2001). DRC: A dual route cascaded model of visual word recognition and reading aloud. Psychological Review, 108, 204256.

Comeau, L., Cormier, P., Grandmaison, É., \& Lacroix, D. (1999). A longitudinal study of phonological processing skills in children learning to read in a second language. Journal of Educational Psychology, 91, 29-43.

Cunningham, A. E., Perry, K. E., \& Stanovich, K. E. (2001). Converging evidence for the concept of orthographic processing. Reading and Writing, 14, 549-568.

Cunningham, A. E., \& Stanovich, K. E. (1990). Assessing print exposure and orthographic processing skill in children: A quick measure of reading experience. Journal of Educational Psychology, $82,733-740$.

Cunningham, A. E., \& Stanovich, K. E. (1993). Children's literacy environments and early word recognition subskills. Reading and Writing, 5, 193-204.

Cutler, A., \& Butterfield, S. (1992). Rhythmic cues to speech segmentation: Evidence from juncture misperception. Journal of Memory and Language, 31, 218-236.

Cutler, A., Mehler, J., Norris, D. G., \& Segui, J. (1986). The syllable's differing role in the segmentation of French and English. Journal of Memory and Language, 25, 385-400.

Cutler, A., \& Otake, T. (1994). Mora or phoneme? Further evidence for language-specific listening. Journal of Memory and Language, 33, 824-844.

D'Angiulli, A., Siegel, L., \& Serra, E. (2001). The development of reading in English and Italian in bilingual children. Applied Psycholinguistics, 22, 479-507.

Deacon, S., \& Kirby, J. R. (2004). Morphological awareness: Just "more phonological"? The roles of morphological and phonological awareness in reading development. Applied Psycholinguistics, $25,223-238$.

Dunn, L., \& Dunn, L. (1997). Peabody Picture Vocabulary Test-III. Circle Pines, MN: American Guidance Service.

Durgunoglu, A. Y., Nagy, W. E., \& Hancin-Bhatt, B. J. (1993). Cross-language transfer of phonological awareness. Journal of Educational Psychology, 85, 453-465.

Ehri, L. C. (1991). Learning to read and spell words. In L. Rieben, \& C. A. Perfetti (Eds.), Learning to read: Basic research and its implications (pp. 57-73). Hillsdale, NJ: Erlbaum.

Ehri, L. C. (1998). Research on learning to read and spell: A personal-historical perspective. Scientific Studies of Reading, 2, 97-114.

Geva, E., \& Siegel, L. (2000). Orthographic and cognitive factors in the concurrent development of basic reading skills in two languages. Reading and Writing: An Interdisciplinary Journal, 12, $1-30$.

Goswami, U., \& Bryant, P. (1990). Phonological skills and learning to read. Hillsdale, NJ: Erlbaum. 
Wang et al.: Chinese-English biliteracy acquisition

Ho, C. S.-H., \& Bryant, P. (1997a). Development of phonological awareness of Chinese children in Hong Kong. Journal of Psycholinguistic Research, 26, 109-126.

Ho, C. S.-H., \& Bryant, P. (1997b). Learning to read Chinese beyond the logographic phase. Reading Research Quarterly, 32, 276-289.

Ho, C. S.-H., \& Bryant, P. (1997c). Phonological skills are important in learning to read Chinese. Developmental Psychology, 33, 946-951.

Hu, C.-F., \& Catts, H. W. (1998). The role of phonological processing in early reading ability: What we can learn from Chinese. Scientific Studies of Reading, 2, 55-79.

Hulme, C., Hatcher, P. J., Nation, K., Brown, A., Adams, J., \& Stuart, G. (2002). Phoneme awareness is a better predictor of early reading skill than onset-rime awareness. Journal of Experimental Child Psychology, 82, 2-28.

Jastak, J. R., \& Jastak, S. R. (1984). Wide Range Achievement Test-Revised. Wilmington, DE: Guidance Associates.

Kang, S., Xu, X., \& Sun, M. (2005). 现代汉语语义构词规则初探 [The research on the modern Chinese semantic word-formation]. Journal of Chinese Language and Computing, 15, 103-112.

$\mathrm{Ku}$, Y. M., \& Anderson, R. C. (2003). Development of morphological awareness in Chinese and English. Reading \& Writing, 16, 399-422.

Kuo, L. J., \& Anderson, R. C. (2007). Conceptual and methodological issues in comparing metalinguistic awareness across languages. In K. Koda \& A. Zehler (Eds.), Learning to read across languages. Mahwah, NJ: Erlbaum.

Li, W., Anderson, R. C., Nagy, W., \& Zhang, H. (2002). Facets of metalinguistic awareness that contribute to Chinese literacy. In W. Li, Gaffney, J. S., \& Packard J. L. (Ed.), Chinese children's reading acquisition: Theoretical and pedagogical issues (pp. 87-106). Norwell, MA: Kluwer Academic.

Liu, Y., \& Perfetti, C. A. (2003). The time course of brain activity in reading English and Chinese: An ERP study of Chinese bilinguals. Human Brain Mapping, 18, 167-175.

Lundberg, I., Olofsson, A., \& Wall, S. (1980). Reading and spelling skills in the first school years predicted from phonemic awareness skills in kindergarten. Scandinavian Journal of Psychology, $21,159-173$.

Lundberg, I., Frost, J., \& Petersen, O.-P. (1988). Effects of an extensive program for stimulating phonological awareness in preschool children. Reading Research Quarterly, 23, 263-284.

McBride-Chang, C., Cho, J.-R., Liu, H., Wagner, R. K., Shu, H., Zhou, A., et al. (2005). Changing models across cultures: Associations of phonological awareness and morphological structure awareness with vocabulary and word recognition in second graders from Beijing, Hong Kong, Korea, and the United States. Journal of Experimental Child Psychology, 92, 140-160.

McBride-Chang, C., \& Ho, C. S. (2000). Developmental Issues in Chinese Children's Character Acquisition. Journal of Educational Psychology, 92, 50-55.

McBride-Chang, C., Shu, H., Zhou, A., Wat, C. P., \& Wagner, R. (2003). Morphological awareness uniquely predicts young children's Chinese character recognition. Journal of Educational Psychology, 95, 743-751.

Muter, V., Hulme, C., Snowling, M., \& Taylor, S. (1998). Segmentation, not rhyming, predicts early progress in learning to read: Erratum. Journal of Experimental Child Psychology, 71, 3-27.

Nagy, W., Berninger, V., Abbott, R., Vaughan, K., \& Vermeulen, K. (2003). Relationship of morphology and other language skills to literacy skills in at-risk second-grade readers and at-risk fourthgrade writers. Journal of Educational Psychology, 95, 730-742.

Nagy, W., Kuo-Kealoha, A., Wu, X., Li, W., Anderson, R. C., \& Chen, X. (2002). The role of morphological awareness in learning to read Chinese. In W. Li, J. S. Gaffiney, \& J. L. Pachard. (Eds.), Chinese children's reading acquisition: Theoretical and pedagogical issues (pp. 58-85). Norwell, MA: Kluwer Academic.

Nagy, W., Berninger, V. W., \& Abbott, R. D. (2006). Contributions of morphology beyond phonology to literacy outcomes of upper elementary and middle-school students. Journal of Educational Psychology, 98, 134-147.

Packard, J. (2000). The morphology of Chinese: A linguistic and cognitive approach. Cambridge: Cambridge University Press.

Peng, D.-L., Li, Y.-P., \& Yang, H. (1997). Orthographic processing in the identification of Chinese characters. In H. C. Chen. (Ed.), Cognitive processing of Chinese and related Asian languages (pp. 86-108). Hong Kong: Chinese University Press. 
Wang et al.: Chinese-English biliteracy acquisition

Perfetti, C. A. (1991). Representations and awareness in the acquisition of reading competence. In L. Rieben \& C. A. Perfetti. (Eds.), Learning to read: Basic research and its implication (pp. 33-44). Hillsdale, NJ: Erlbaum.

Perfetti, C. A. (1992). The representation problem in reading acquisition. In P. B. Gough, L. C. Ehri, \& R. Treiman. (Eds.), Reading acquisition (pp. 145-174). Hillsdale, NJ: Erlbaum.

Perfetti, C. A., Beck, I., Bell, L., \& Hughes, C. (1987). Phonemic knowledge and learning to read are reciprocal: A longitudinal study of first grade children. Merrill-Palmer Quarterly, 33, 283-319.

Perfetti, C. A., Liu, Y., \& Tan, L. H. (2005). The lexical constituency model: Some implications of research on Chinese for general theories of reading. Psychological Review, 112, 43-59.

Plaut, D. C., McClelland, J. L., Seidenberg, M. S., \& Patterson, K. (1996). Understanding normal and impaired word reading: Computational principles in quasi-regular domains. Psychological Review, 103, 56-115.

Read, C., Zhang, Y.-F., Nie, H.-Y., \& Ding, B.-Q. (1986). The ability to manipulate speech sounds depends on knowing alphabetic writing. Cognition, 24, 31-44.

Reed, M. A. (1989). Speech perception and the discrimination of brief auditory cues in reading disabled children. Journal of Experimental Child Psychology, 48, 270-292.

Seidenberg, M. S., \& McClelland, J. L. (1989). A distributed, developmental model of word recognition and naming. Psychological Review, 96, 523-568.

Share, D. (1995). Phonological recoding and self-teaching: Sine qua non of reading acquisition. Cognition, 55, 151-218.

Share, D. L., Jorm, A. F., Maclean, R., \& Matthews, R. (2002). Temporal processing and reading disability. Reading and Writing: An Interdisciplinary Journal, 15, 151-178.

Shu, H., \& Anderson, R. C. (1999). Learning to read Chinese: The development of metalinguistic awareness. In J. Wang, A. W. Inhoff, \& H. C. Chen. (Eds.), Reading Chinese script: A cognitive analysis (pp. 1-18). Mahwah, NJ: Erlbaum.

Shu, H., Anderson, R. C., \& Wu, N. N. (2000). Phonetic awareness: Knowledge of orthographyphonology relationships in the character acquisition of Chinese children. Journal of Educational Psychology, 92, 56-62.

Shu, H., McBride-Chang, C., Wu, S., \& Liu, H. (2006). Understanding Chinese developmental dyslexia: Morphological awareness as a core cognitive construct. Journal of Educational Psychology, $98,122-133$.

Siegel, L. S., Share, D., \& Geva, E. (1995). Evidence for superior orthographic skills in dyslexics. Psychological Science, 6, 250-254.

Stanovich, K. E., Cunningham, A. E., \& Cramer, B. B. (1984). Assessing phonological awareness in kindergarten children: Issues of task comparability. Journal of Experimental Child Psychology, $38,175-190$.

Taft, M., Zhu, X., \& Peng, D. (1999). Positional specificity of radicals in Chinese character recognition. Journal of Memory and Language, 40, 498-519.

Tallal, P. (1980). Auditory temporal perception, phonics, and reading disabilities in children. Brain \& Language, 9, 182-198.

Tan, L. H., Liu, H.-L., Perfetti, C. A., Spinks, J. A., Fox, P. T., \& Gao, J.-H. (2001). The neural system underlying Chinese logographic reading. NeuroImage, 13, 836-846.

Tan, L. H., Spinks, J. A., Feng, C. M., Siok, W. T., Perfetti, C. A., Xiong, J., Fox, P., \& Gao, J. H. (2003). Neural systems of second language reading are shaped by native language. Human Brain Mapping, 18, 158-166.

Treiman, R. (1993). Beginning to spell. New York: Oxford University Press.

Treiman, R., \& Cassar, M. (1997). Can children and adults focus on sound as opposed to spelling in a phoneme counting task? Developmental Psychology, 33, 771-780.

Wang, M., Cheng, C., \& Chen, S. (2006). Contribution of morphological awareness to Chinese-English biliteracy acquisition. Journal of Educational Psychology, 98, 542-553.

Wang, M., Park, Y., \& Lee, K. R. (2006). Korean-English biliteracy acquisition: Cross language phonological and orthographic transfer. Journal of Educational Psychology, 98, 148-158.

Wang, M., Perfetti, C. A., \& Liu, Y. (2005). Chinese-English biliteracy acquisition: cross-language and writing system transfer. Cognition, 97, 67-88.

Woodcock, R. C. (1987). Woodcock Reading Mastery Test. Circle Press, MN: American Guidance Service. 